\title{
Gemcitabine/cannabinoid combination triggers autophagy in pancreatic cancer cells through a ROS-mediated mechanism
}

\author{
M Donadelli ${ }^{1}$, I Dando ${ }^{1,6}$, T Zaniboni ${ }^{1,6}$, C Costanzo ${ }^{1}$, E Dalla Pozza ${ }^{1}$, MT Scupoli ${ }^{2}$, A Scarpa ${ }^{3}$, S Zappavigna ${ }^{4}$, M Marra ${ }^{4}$, \\ A Abbruzzese ${ }^{4}, M_{\text {Bifulco }}{ }^{5}, M_{\text {Caraglia }}{ }^{4}$ and $M$ Palmieri' ${ }^{, 1}$
}

Gemcitabine (GEM, 2',2'-difluorodeoxycytidine) is currently used in advanced pancreatic adenocarcinoma, with a response rate of $<20 \%$. The purpose of our work was to improve GEM activity by addition of cannabinoids. Here, we show that GEM induces both cannabinoid receptor-1 (CB1) and cannabinoid receptor-2 (CB2) receptors by an NF- $\kappa$ B-dependent mechanism and that its association with cannabinoids synergistically inhibits pancreatic adenocarcinoma cell growth and increases reactive oxygen species (ROS) induced by single treatments. The antiproliferative synergism is prevented by the radical scavenger $\mathrm{N}$-acetylL-cysteine and by the specific NF- $\kappa$ B inhibitor BAY 11-7085, demonstrating that the induction of ROS by GEM/cannabinoids and of NF- $\kappa$ B by GEM is required for this effect. In addition, we report that neither apoptotic nor cytostatic mechanisms are responsible for the synergistic cell growth inhibition, which is strictly associated with the enhancement of endoplasmic reticulum stress and autophagic cell death. Noteworthy, the antiproliferative synergism is stronger in GEM-resistant pancreatic cancer cell lines compared with GEM-sensitive pancreatic cancer cell lines. The combined treatment strongly inhibits growth of human pancreatic tumor cells xenografted in nude mice without apparent toxic effects. These findings support a key role of the ROS-dependent activation of an autophagic program in the synergistic growth inhibition induced by GEM/cannabinoid combination in human pancreatic cancer cells.

Cell Death and Disease (2011) 2, e152; doi:10.1038/cddis.2011.36; published online 28 April 2011

Subject Category: Cancer

Pancreatic adenocarcinoma is one of the most aggressive and devastating human malignancies with a death-toincidence ratio of 0.99 . Although it represents only $2-3 \%$ of all cancers, pancreatic adenocarcinoma is the fourth cause of death by tumors. ${ }^{1}$ At diagnosis, $<20 \%$ of patients are candidates for surgery with curative intent. ${ }^{2}$ Monotherapy with gemcitabine (GEM, 2' $2^{\prime}$-difluorodeoxycytidine) has been the standard treatment during the last decade for its modest improvement in the quality of life of patients, although it has a response rate of $<20 \%$. $^{3}$ Many clinical trials have failed to demonstrate an improvement in overall survival with the addition of different drugs to GEM, including cetuximab and bevacizumab. ${ }^{1}$ Nevertheless, some modest but interesting advances have been provided by drug combination therapies, such as GEM-erlotinib, GEM-capecitabine, and GEMplatinum salt. $^{2}$ Nowadays, research is focused on the identification of novel potential targets to efficiently enhance GEM antitumor activity. Reactive oxygen species (ROS) have recently emerged as promising targets for anticancer drug discovery. Indeed, constitutively elevated levels of ROS represent a specific vulnerability of malignant cells that can be selectively targeted by pro-oxidant drugs. ${ }^{4}$ Accordingly, we have recently demonstrated that the induction of ROS is one of the mechanisms of GEM antitumor action and that pancreatic adenocarcinoma cell lines with lower basal levels of ROS are more resistant to GEM compared with cells with higher ROS levels. ${ }^{5}$

In recent years, there has been increasing interest in cannabinoids as therapeutic drugs for their antineoplastic, anticachectic, and analgesic potential. Growth inhibitory activities of cannabinoids have been demonstrated for various malignancies, including brain, breast, prostate, colorectal, skin and, recently, pancreatic cancer. ${ }^{6,7}$ Cannabinoid effects are mediated through the activation of G-protein-coupled receptors, namely cannabinoid receptor- 1 (CB1) ${ }^{8}$ and cannabinoid receptor-2 (CB2). ${ }^{9}$ Noteworthy, these receptors are overexpressed in several tumors, including pancreatic adenocarcinoma, whereas they are undetectable or expressed at low level in normal tissues, ${ }^{10}$ suggesting that a cannabinoid-based therapy may activate cell death pathways predominantly in

\footnotetext{
${ }^{1}$ Department of Life and Reproduction Sciences, Biochemistry Section, University of Verona, Verona, Italy; ${ }^{2}$ Interdepartmental Laboratory for Medical Research, University of Verona, Verona, Italy; ${ }^{3}$ Department of Pathology and Diagnostics, University of Verona, Verona, Italy; ${ }^{4}$ Department of Biochemistry and Biophysics, II University of Naples, Naples, Italy and ${ }^{5}$ Department of Pharmaceutical and Biomedical Sciences, University of Salerno, Fisciano, Italy

*Corresponding author: M Palmieri, Department of Life and Reproduction Sciences, Biochemistry Section, University of Verona, Strada Le Grazie 8, Verona 37134 , Italy. Tel: + 39045802 7169; Fax: + 39045802 7170; E-mail: marta.palmieri@univr.it

${ }^{6}$ These authors equally contributed to this work.

Keywords: pancreatic cancer; reactive oxygen species; gemcitabine; cannabinoid; ER stress; autophagy

Abbreviations: IRE1, inositol-requiring ER to nucleus signal kinase 1; XBP-1, X-box-binding protein-1; PERK, RNA-dependent protein kinase-like ER kinase; ATF-6, activating transcription factor-6; CHOP, CCAAT/enhancer-binding protein (C/EBP) homologous protein; GRP78, glucose-regulated protein $78 \mathrm{kDa}$; LC3, microtubuleassociated protein 1 light-chain $3 \alpha$; ATG5, autophagy-related 5 homolog; BIM, Bcl-2-like protein 11; Bcl-2, B-cell lymphoma gene-2

Received 03.2.11; revised 22.3.11; accepted 29.3.11; Edited by G Melino
} 
tumor cells. A causal relationship between ROS production and cell death has also been demonstrated in cannabinoidinduced cell growth inhibition. In this regard, Sarker et al. ${ }^{11}$ have shown that the cannabinoid anandamide induces apoptosis of PC-12 cells by increasing superoxide levels. Furthermore, it has been observed that cannabinoid administration in rats induces cerebral lipoperoxidation under ex vivo conditions. ${ }^{12}$ Recent findings have shown that the tumor growth-inhibiting activity of cannabinoids relies on the upregulation of the endoplasmic reticulum (ER) stress pathway ${ }^{13}$ and that ROS enhancement can determine perturbations of ER homeostasis affecting protein folding, thus causing ER stress. ${ }^{14} \mathrm{ER}$ stress response involves translational attenuation, upregulation of ER chaperone genes and related proteins, and degradation of unfolded proteins by a quality-control system. ${ }^{15}$ The ER resident transmembrane kinase/endoribonuclease IRE1 (inositol-requiring ER to nucleus signal kinase 1 ) is a primary ER sensor for unfolded proteins. ${ }^{16}$ It transmits this information to the cytosol by activating its endoribonuclease domain, which initiates an unconventional $\mathrm{mRNA}$-splicing reaction of the transcriptional activator XBP-1 (X-box-binding protein-1). ${ }^{15}$ The other sensors of ER stress are the transmembrane proteins PERK (RNA-dependent protein kinase-like ER kinase) and ATF-6 (activating transcription factor-6). ${ }^{16}$ In concert, these three pathways stimulate the expression of a set of proteins involved in ER stress response including the luminal ER chaperone Grp78 (glucose-regulated protein $78 \mathrm{kDa}$; BiP). ${ }^{17}$ However, when the ER function is severely impaired, the organelle elicits cell death signals through activation of $\mathrm{CHOP}$ (CCAAT/enhancer-binding protein (C/EBP) homologous protein; GADD153), ${ }^{17}$ which in turn is described to promote apoptosis by $\mathrm{B}$-cell lymphoma gene-2 (Bcl-2)-like protein 11 (BIM) induction and $\mathrm{Bcl}-2$ inhibition, ${ }^{18}$ and/or autophagy by LC3 (microtubule-associated protein 1 light-chain $3 \alpha$ ) and ATG5 (autophagy-related 5 homolog) induction. ${ }^{19}$

Autophagy is a highly conserved cellular process in which cytoplasmic materials, including organelles, are sequestered into double-membrane vesicles called autophagosomes and delivered to lysosomes for degradation or recycling. Besides its cytoprotective role in cellular homeostasis, for example in situations of nutrient starvation, autophagy can be a form of programmed cell death, designated type II programmed cell death'. 20

In the present study, we have investigated the effect of the combination between GEM and three different CB ligands, arachidonoyl cyclopropamide (ACPA) and SR141716 (SR1) for CB1, and GW405833 (GW) for CB2 on pancreatic adenocarcinoma cell growth. Our results show that GEM induces both $\mathrm{CB} 1$ and $\mathrm{CB} 2$ receptors by an NF- $\kappa \mathrm{B}$-dependent mechanism. Moreover, we demonstrate that all the three cannabinoids determine ROS production, ER stress, and autophagic cell death, and that these effects are potentiated by GEM. GEM/cannabinoid treatment produces a strong synergistic inhibition of pancreatic cancer cell growth in vitro, and significantly enhances the antitumoral effect of GEM in vivo. The same treatment is ineffective on normal fibroblasts and does not determine apparent toxicity in nude mice. Altogether, these data strongly support the development of GEM/cannabinoid treatment in the management of pancreatic cancer.

\section{Results}

GEM/cannabinoid combined treatments synergistically inhibited pancreatic adenocarcinoma cell proliferation. The antiproliferative effect of the synthetic cannabinoids GW, ACPA, and SR1 in combination with GEM was examined on six pancreatic adenocarcinoma cell lines characterized by different sensitivities to GEM. As reported in our previous papers, ${ }^{5}$ CFPAC1, T3M4, and MiaPaCa2 cells are more sensitive to GEM treatment than PaCa3, PaCa44, and Panc1 cells. Figure 1a shows that the combined treatments significantly enhanced Panc1 cell growth inhibition compared with single treatments. Similar results were obtained with all the pancreatic adenocarcinoma cell lines assessed in this study (data not shown). On the contrary, normal fibroblasts were significantly less sensitive to cannabinoids and their growth was not further inhibited by GEM addition. To analyze the trend of the inhibitory effect over the time, we performed a time-dependent analysis of the antiproliferative activity following a $24-\mathrm{h}$ single-step treatment with low concentrations of GEM and/or cannabinoids. Figure $1 \mathrm{~b}$ shows that, starting from the fourth day, only the combined treatments were able to significantly inhibit Panc1 cell proliferation, with a growth ratio inhibition at the sixth day in treated versus untreated cells of 48,36 , and $57 \%$ for GEM/GW, GEM/ACPA, and GEM/SR1, respectively.

To evaluate whether cell growth inhibition by GEM/ cannabinoids was synergistic, we analyzed cell growth inhibition curves by using the dedicated software CalcuSyn (Biosoft, Ferguson, MO, USA; see 'Materials and Methods'). Figure 1c reports the percentages of the combination index (Cl) values encompassed between 1 and 0.3 (synergism) or lower than 0.3 (strong synergism) for all combinations. Although GEM-resistant cell lines showed percentages of the overall synergism $(\mathrm{Cl}<1)$ similar to those of GEMsensitive cell lines, they had a level of strong synergism $(\mathrm{Cl}<0.3)$ significantly higher than that of the latter cell lines (Supplementary Figure 1). This result suggests that cannabinoids sensitize cancer cells to the antiproliferative effects caused by GEM. Supplementary Table 1 shows that in the resistant Panc1 cells, cannabinoids potentiated the effects of GEM from 5- to 10-fold (PF). Similar results were obtained with the other GEM-resistant cells (data not shown). On the other hand, in agreement with data shown in Figure 1a, GEM/ cannabinoid combinations did not determine any synergism in normal fibroblasts.

GEM/cannabinoid combined treatments enhanced intracellular ROS production. As it was previously reported that the antiproliferative effect of GEM or cannabinoids is mediated by oxidative stress, ${ }^{5,21}$ we measured ROS levels in Panc1 cells treated with increasing concentrations of the single compounds or their combinations. Figure 2 shows that GEM/cannabinoids were able to significantly enhance ROS production, induced by single treatments, at $4 \mathrm{~h}$. Similar enhancement was obtained at $16 \mathrm{~h}$ (data not shown).

GEM induced cannabinoid receptor expression by NF- $\kappa$ B-mediated mechanism. To investigate whether GEM was able to regulate cannabinoid receptor 


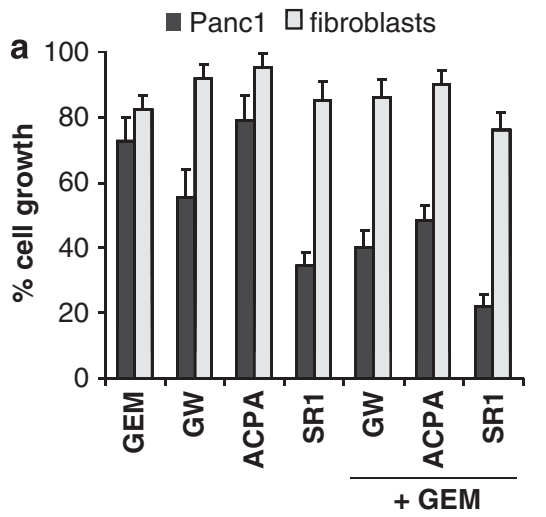

b

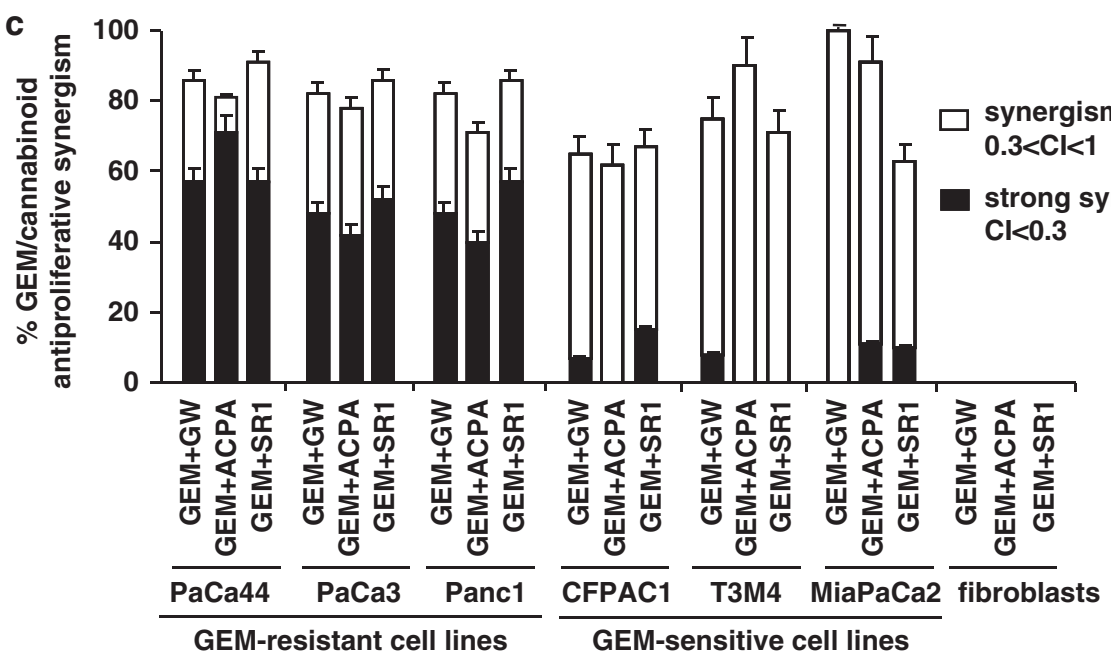

Figure 1 Effect of GEM and/or GW, ACPA, or SR1 on growth of pancreatic adenocarcinoma cell lines and normal fibroblasts. (a) Cells were seeded in 96-well plates and incubated overnight. The compounds were added at the concentrations of $200 \mathrm{nM} \mathrm{GEM}, 16 \mu \mathrm{M} \mathrm{SR} 1$ and GW, and $90 \mu \mathrm{M} \mathrm{ACPA}$; cells were incubated for additional $48 \mathrm{~h}$. Values are reported as percentage of treated versus untreated cells, and are the means of triplicate samples from three independent experiments ( \pm S.D.). Statistical analysis: $P<0.001$, GEM versus each combination; $P<0.01$, each cannabinoid versus its combination with GEM in Panc1 cells, no significance between the various treatments in fibroblasts. (b) Panc1 cells were seeded in 96-well plates and incubated overnight. The compounds were added at the following concentrations for $24 \mathrm{~h}: 25 \mathrm{nM}$ GEM, $2 \mu \mathrm{M}$ SR1 and GW, and 11.25 $\mu \mathrm{M}$ ACPA. The growth ratio on the $y$ axis was obtained by dividing the absorbance of untreated or treated cell lines by the mean absorbance of each cell line measured at time 0 . Values are the means of triplicate samples from three independent experiments ( \pm S.D.). The statistical analysis was performed for each combined treatment versus control. (c) Antiproliferative synergism by GEM/cannabinoids. The percentage values were obtained by analyzing $\mathrm{Cl} /$ effect curves, as described in Materials and Methods. Statistical analysis: $P<0.001, \% \mathrm{Cl}<1$ in all cancer cell lines versus normal fibroblasts

expression, we performed a time-dependent analysis of the mRNA for CB1 and CB2 receptors on Panc1 cells. As shown in Figure 3a and Supplementary Figure 2, GEM determined an approximately fourfold and sevenfold induction of CB1 and CB2 mRNAs, respectively. CB mRNAs induction by GEM was transcriptionally regulated, as their increase was completely antagonized by the addition of actinomycin D (ActD). Similarly, both CB1 and CB2 mRNA GEM-mediated increase was completely blocked by three NF- $\kappa$ B inhibitors (BAY, pyrrolidine dithiocarbamate (PDTC), and MG132), but not by the free radical scavenger $N$-acetyl-L-cysteine (NAC; Figure 3b). IL-1, a known NF- $\kappa$ B inducer, stimulated both $\mathrm{CB} 1$ and $\mathrm{CB} 2$ expression, which was antagonized by MG132 addition. Moreover, the antiproliferative synergism was significantly reduced by MG132 and completely abrogated by BAY (Figure 3c). Altogether, these data indicate that NF- $\kappa \mathrm{B}$ is involved in both ROS-independent cannabinoid receptor induction by GEM and in the antiproliferative synergism by GEM/cannabinoid combinations, suggesting a role for $\mathrm{CB} 1$ and $\mathrm{CB} 2$ activation by GEM in the latter effect.

GEM enhanced cannabinoid-induced ER stress. It was previously reported that ER stress is a molecular mechanism involved in cannabinoid antiproliferative effect. ${ }^{13}$ To investigate whether GEM was able to enhance the cannabinoid-induced ER stress, we analyzed mRNA expression of the ER stress sensors XBP-1, Grp78, and $\mathrm{CHOP}$ following single or combined treatments. Figure 4 shows that all the three mRNAs were induced by GW, ACPA, or SR1, and their levels were significantly enhanced by the addition of GEM, even if GEM alone was ineffective.

GEM enhanced cannabinoid-induced autophagy by a ROS-mediated mechanism. To determine whether apoptosis and/or cell cycle arrest were involved in the 


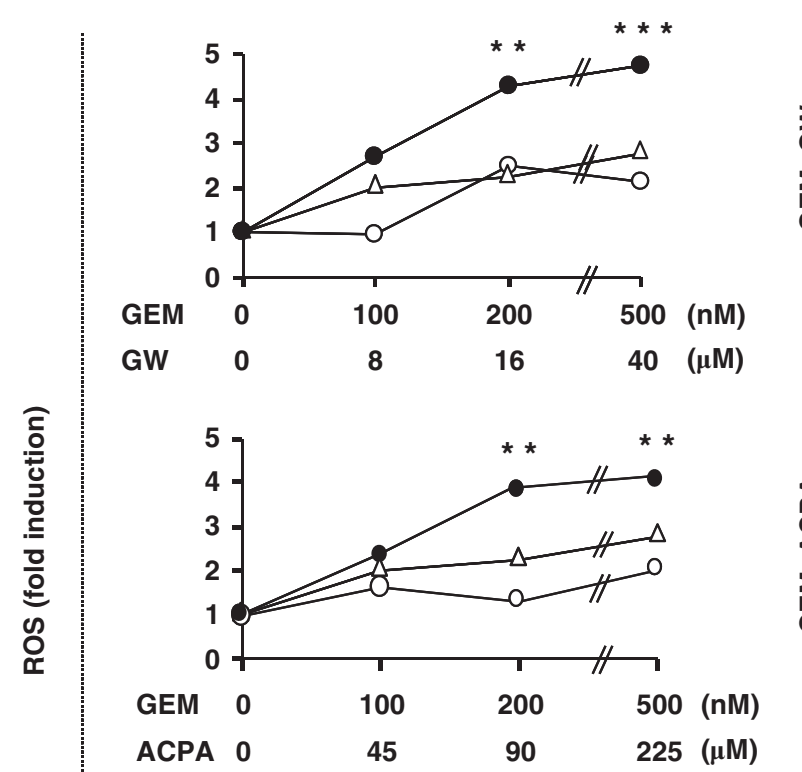

矛

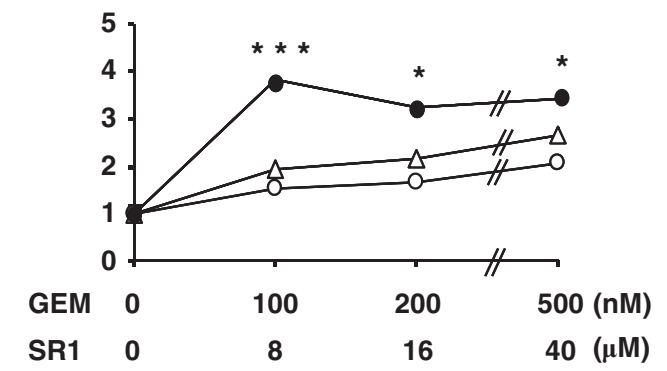

\section{$\triangle$ GEM cannabinoid GEM + cannabinoid}

Figure 2 Effect of GEM and/or cannabinoids on intracellular ROS production. Panc1 cells were treated with increasing concentrations of the compounds for $4 \mathrm{~h}$ at constant dose ratios, as reported in Materials and Methods. The DCF fluorescence intensity, corresponding to the level of ROS production, was measured by a multimode plate reader. Values are the means of triplicate samples from three independent experiments. The statistical analysis was performed for each combined treatment versus single treatments

antiproliferative synergism between GEM and cannabinoids, we performed both annexin V-FITC/propidium iodide (PI) assay and cell cycle analysis by flow cytometry after single or combined treatments. Figure 5 a shows that GEM, but not cannabinoids, significantly induced apoptosis at $48 \mathrm{~h}$. This effect was partially reduced by the addition of cannabinoids. Similar results were obtained at $24 \mathrm{~h}$, and with $\mathrm{PaCa} 44$ and T3M4 cell lines (data not shown). Figure 5b shows that GEM increased the percentages of cells in $\mathrm{G} 1$ and $\mathrm{S}$ phases and cannabinoids in $\mathrm{G} 1$ phase, and the combined treatments did not induce a potentiation of the accumulation of cells in a particular phase of cell cycle when compared with the changes induced by GEM or cannabinoids alone. Altogether, these data indicate that GEM/cannabinoid synergism is likely mediated by neither apoptotic nor cell cycle modulation.

Recently, Salazar et al. ${ }^{13}$ reported that tetrahydrocannabinol (THC) is able to induce autophagy-mediated cell death in human glioma cells. Therefore, we investigated whether $\mathrm{GW}$, ACPA, or SR1 also were able to induce autophagy and whether GEM could additionally enhance this effect.
Figure $5 \mathrm{c}$ shows that at $24 \mathrm{~h}$ LC3-II protein, the phosphoethanolaminated form of the autophagosome protein LC3-I, was increased by single treatments with GEM or cannabinoids and additionally enhanced by GEM/cannabinoid combinations. Similar results were obtained at $48 \mathrm{~h}$ (data not shown). A late step in the autophagic cell death process is the fusion of lysosomes with autophagosomes into autolysosomes, which can be detected by measuring their acidification with acridine orange staining. Interestingly, we found acridine orange staining (characterized by a punctuation, suggesting vacuole formation) slightly increased in GEM or cannabinoidtreated cells and significantly potentiated in cells treated with GEM/cannabinoid combinations (Figure 6a). These effects were almost completely antagonized by the addition of either the scavenger NAC or the autophagy inhibitors $\mathrm{CQ}$ or 3methyladenine (3-MA). This observation was confirmed by FACS analysis, which shows a significant difference in the acidification of the acidic vesicular organelles (AVOs) in pancreatic cancer cells treated with GEM or cannabinoids compared with control, and with GEM/cannabinoid combination compared with single treatments (Figure 6b). Blocking autophagy with 3-MA or $\mathrm{CQ}$ resulted in a decrease in autolysosomal acidification, demonstrating that acidification induced by the different combinations was linked to the autophagic pathway.

To ascertain whether the presence of numerous cytoplasmic vacuoles in GEM/combination-treated cells was really due to the induction of autophagy, the autofluorescent drug monodansylcadaverine (MDC), a selective marker for AVOs, such as autophagic vacuoles and especially autolysosomes, was used. ${ }^{22}$ Figure $6 \mathrm{c}$ shows the quantitative evaluation of MDC staining performed by FACS. We again found that GEM, SR-1, and ACPA induced a similar increase in AVO formation, which was more prominent in GW-treated cells. This effect was strongly potentiated by the GEM/cannabinoid combinations and antagonized by the autophagy inhibitors CQ or 3-MA or the scavenger NAC.

Figure 7a shows that either NAC, CQ, or 3-MA strongly reduced the percentages of the antiproliferative synergism by GEM/cannabinoids. Similar results were obtained with $\mathrm{PaCa} 44$ and $\mathrm{PaCa} 3$ cell lines (data not shown). It is worth to note that the NAC concentration used in these experiments $(20 \mathrm{mM})$ was non-toxic by itself and was able to completely abolish ROS induction by GEM/cannabinoids (data not shown). Altogether, these data demonstrate that GEM enhances cannabinoid-induced autophagy by a ROSmediated mechanism and that this event is required for GEM/cannabinoid synergism. Figures $7 b$ and $c$ show a kinetic analysis of the events involved in GEM/cannabinoid antiproliferative synergism, that is, oxidative stress, ER stress, and autophagy. Although ROS were induced within $4 \mathrm{~h}$, the peak of Grp78 and LC3-II protein expression appeared at 8 and 12/16 h, respectively, suggesting that ER stress could be a mechanism connecting ROS induction with autophagic cell death.

GEM and cannabinoids strongly inhibited growth of human pancreatic adenocarcinoma cells in vivo. The effect of GEM and/or SR1 on growth inhibition of PaCa44 cells subcutaneously xenografted in nude mice was also investigated. Figure $8 \mathrm{a}$ shows that the volume of tumor in 

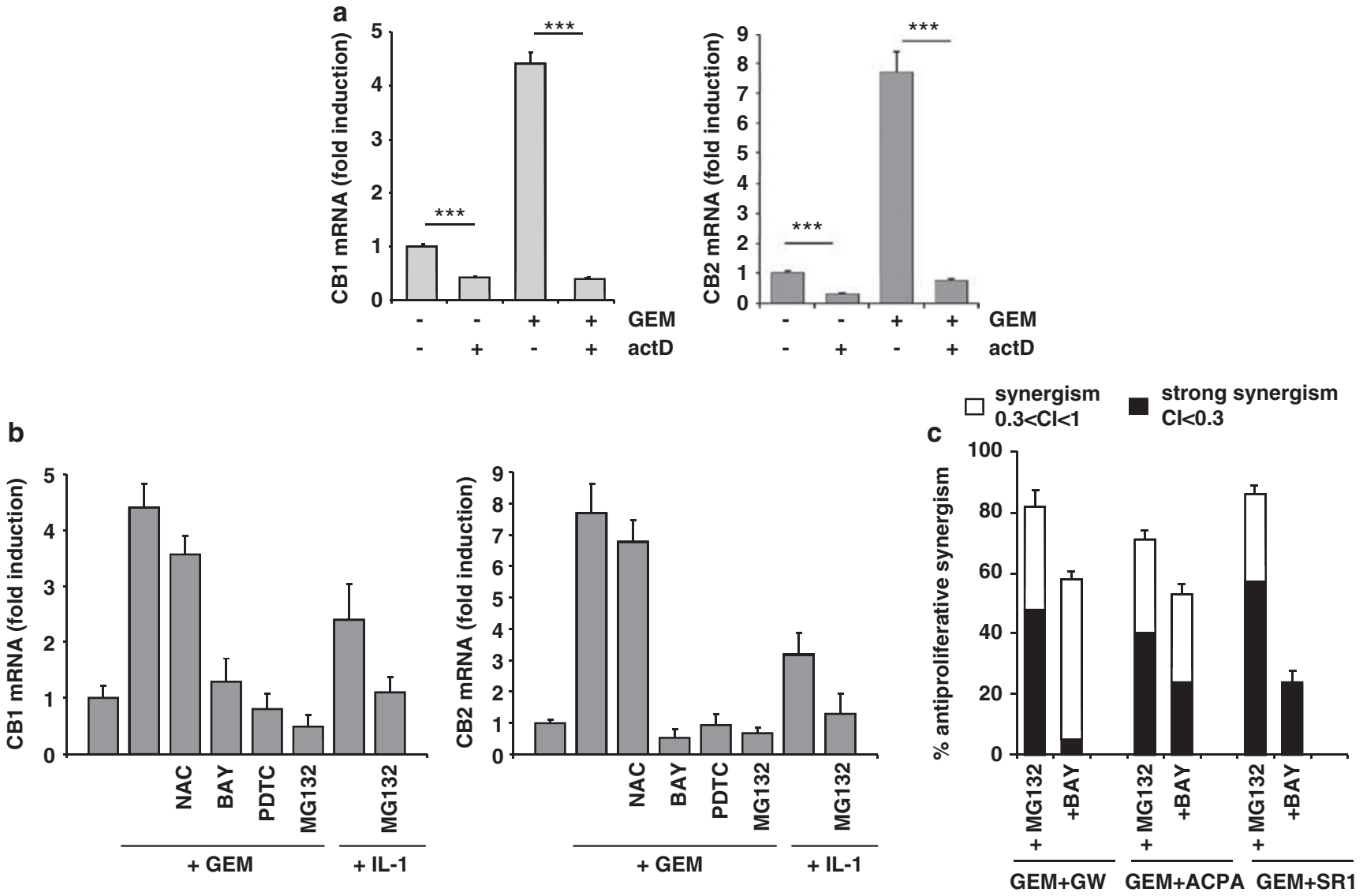

Figure 3 Role of NF- $\kappa$ B in CB1 and CB2 activation by GEM and in the antiproliferative synergism by GEM/cannabinoids. (a) Panc1 cells were seeded in 60 -mm plates and incubated overnight. Cells were pretreated with $5 \mu \mathrm{g} / \mathrm{ml} \mathrm{ActD}$ for $1 \mathrm{~h}$, then $2 \mu \mathrm{M} \mathrm{GEM}$ was added, and the treatments prolonged up to $16 \mathrm{~h}$. Total RNA extraction and real-time PCR were performed, as described in Materials and Methods. Values are the means of triplicate samples from four independent experiments ( \pm S.D.). (b) qPCR analysis of $\mathrm{CB} 1$ and CB2 mRNAs from cells treated with $2 \mu \mathrm{M}$ GEM or $10 \mu \mathrm{g} / \mathrm{ml} \mathrm{IL-1}$. In all, $10 \mathrm{mM} \mathrm{NAC,} 10 \mu \mathrm{M} \mathrm{BAY,} 100 \mu \mathrm{M}$ PDTC, or $100 \mu \mathrm{M}$ MG132, where indicated, were added $1 \mathrm{~h}$ before treatments. $\mathrm{CB} 1$ and $\mathrm{CB} 2 \mathrm{mRNAs}$ were analyzed at $16 \mathrm{~h}$. Values are the means of triplicate samples from three independent experiments ( \pm S.D.). Statistical analysis: $P<0.001$, control versus GEM or GEM + NAC and $P<0.001$, GEM versus GEM + MG132, GEM + BAY, or GEM + PDTC. $P<0.001$, IL-1 versus IL-1 + MG132 (for both $\mathrm{CB} 1$ and CB2). (c) Analysis of the antiproliferative synergism by $2 \mu \mathrm{M}$ GEM and $40 \mu \mathrm{M} \mathrm{GW}, 225 \mu \mathrm{M} \mathrm{ACPA}$, or $40 \mu \mathrm{M}$ SR1 in the absence or presence of $100 \mathrm{nM}$ MG132 or $1 \mu \mathrm{M}$ BAY. Values are the means of three independent experiments ( \pm S.D.). Statistical analysis for total synergism $(0.3<\mathrm{Cl}<1): P<0.001, \mathrm{GEM}+\mathrm{GW}$ versus $\mathrm{GEM}+\mathrm{GW}+\mathrm{BAY} ; \mathrm{P}<0.001$, GEM + ACPA versus GEM + ACPA + BAY; $P<0.001, \mathrm{GEM}+\mathrm{SR} 1$ versus GEM + SR $1+\mathrm{MG}$ or GEM + SR $1+\mathrm{BAY} ; P<0.05$, GEM + GW versus GEM + GW + MG; and $P<0.05, \mathrm{GEM}+\mathrm{ACPA}$ versus GEM + ACPA + MG. Statistical analysis for high synergism $(\mathrm{Cl}<0.3): P<0.001, \mathrm{GEM}+\mathrm{GW}$ versus GEM + GW + MG or GEM + GW + BAY; $P<0.001$, GEM + SR1 versus GEM + SR1 + BAY; $P<0.01, G E M+A C P A$ versus GEM + ACPA + BAY; $P<0.01$, $\mathrm{GEM}+\mathrm{SR} 1$ versus $\mathrm{GEM}+\mathrm{SR} 1+\mathrm{BAY}$; and $P<0.05, \mathrm{GEM}+\mathrm{ACPA}$ versus GEM + ACPA + MG

mice treated with the combination GEM + SR1 remained essentially unchanged during the observation time, whereas it increased considerably in the control group and, at a lower extent, in either GEM- or SR1-treated groups. Figure 8b shows that mice body masses did not change during the experiment, suggesting that the treatments did not produce any apparent toxicity. At the end of the treatment time, the percentages of mean tumor mass reduction relative to control were 65,34 , or $92 \%$ in mice treated with GEM, $\mathrm{SR} 1$, or GEM + SR1, respectively (Figure $8 \mathrm{c}$ ).

\section{Discussion}

In the present study, we have demonstrated that the combination between the standard chemotherapy agent GEM and cannabinoids synergistically inhibited pancreatic adenocarcinoma cell growth by a ROS-dependent autophagic cell death. We used highly specific cannabinoid ligands of CB1 (ACPA) and CB2 (GW), and the clinically relevant CB1 ligand SR1. The latter has been described as a CB1 antagonist or inverse agonist; ${ }^{23}$ however, at high concentration it possesses an agonist activity. ${ }^{24}$ Our results were in agreement with the last observation and additionally confirmed the dual and concentration-dependent effect of SR1 on cell response (data not shown). SR1 counteracts obesity and its metabolic complications regulating food intake at central and peripheral level ${ }^{25}$ and also exerts antitumoral activity in some cancer types and in thyroid tumor xenografts. ${ }^{26}$ In contrast to SR1, to our knowledge, the antitumor activity of ACPA and GW has never been reported before. Thus, our results show for the first time that GW, ACPA, or SR1, in addition to GEM, were able to synergistically inhibit pancreatic adenocarcinoma cell growth. Our data also demonstrated that low concentrations of GEM/cannabinoids added to the cells 
a

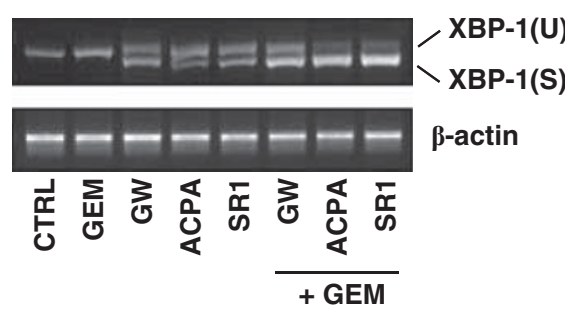

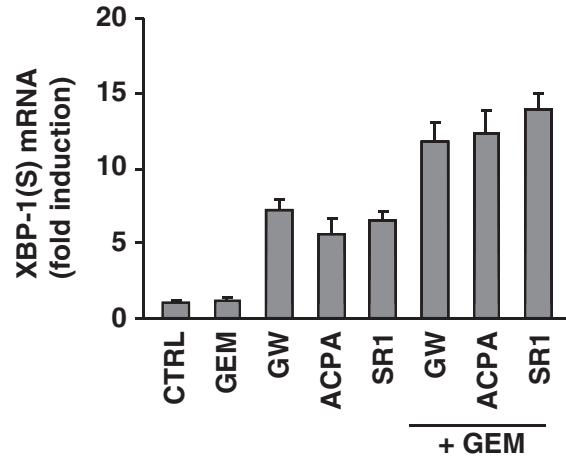

C

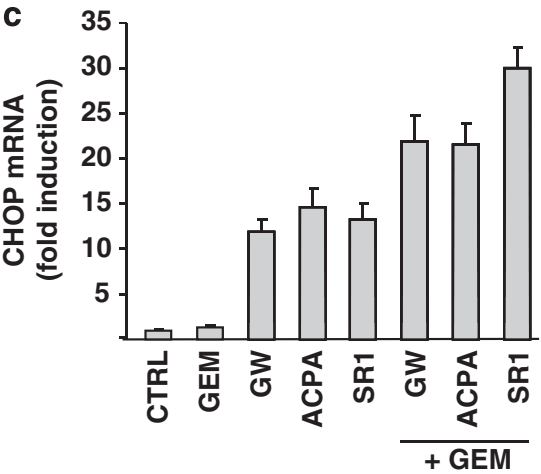

Figure 4 Effect of GEM and/or cannabinoids on ER stress-related gene expression. Panc1 cells were treated with $500 \mathrm{nM}$ GEM and/or $40 \mu \mathrm{M} \mathrm{GW}, 225 \mu \mathrm{M} \mathrm{ACPA}$, or $40 \mu \mathrm{M}$ SR1 for $8 \mathrm{~h}$. RT-PCR for XBP-1(S) and qPCR for Grp78 and CHOP were performed, as described in Materials and Methods. Densitometric analysis of XBP-1(S) was normalized to $\beta$-actin and performed, as described in Materials and Methods. Values are the means of triplicate samples from three independent experiments ( \pm S.D.). Statistical analysis: $P<0.001$, GEM versus each cannabinoid and each cannabinoid versus its combination with GEM (for all the three genes)

for $24 \mathrm{~h}$ were able to significantly reduce pancreatic adenocarcinoma cell growth at least for 6 days from the beginning of the treatment. This result may be clinically relevant, suggesting the possibility to set up therapeutic protocols for pancreatic cancer with low concentrations of GEM/cannabinoids that may give reduced side effects. Our data also show that cannabinoids were quite ineffective in normal fibroblasts, and combined treatments with GEM does not further increase cell growth inhibition. These results are in agreement with the observation that cannabinoid receptors are overexpressed in cancer cells, whereas they are undetectable or expressed at low levels in normal cells ${ }^{10}$ and that GEM is selectively active in cancer cells, which generally show a higher growth rate as compared with the normal counterpart. Recently, our research group has reported that $\mathrm{p} 53^{-/-}$pancreatic adenocarcinoma cell growth is strongly inhibited by ROS-inducing compounds. $^{27,28}$ Moreover, we have demonstrated that pancreatic adenocarcinoma cell growth inhibition by GEM is due, at least in part, to ROS induction and that cell lines with lower basal levels of ROS are more resistant to GEM compared with cells with higher ROS levels. ${ }^{5}$ Here, we report that GEM-resistant cell lines showed a significantly higher synergism $(\mathrm{Cl}<0.3)$ of cell growth inhibition by $\mathrm{GEM} /$ cannabinoids compared with GEM-sensitive cell lines and that the synergism was dependent on the increase in intracellular ROS induced by the combinations. This mechanism is supported by the observation that the radical scavenger NAC totally inhibited the synergistic antiproliferative effect induced by GEM/cannabinoids. These findings strongly support the idea that the increase in ROS production may be a good strategy to overcome GEM resistance in the therapeutic management of pancreatic cancer.

It has previously been described that cannabinoid receptor overexpression can potentiate cannabinoid antitumor effects. ${ }^{29}$ Here, we report for the first time that GEM treatment determined CB1 and CB2 transcriptional induction, suggesting its involvement in GEM/cannabinoid-induced synergism on cell growth inhibition. The regulation of $C B 1$ and $C B 2$ gene expression is currently poorly studied. Recently, Borner et al. $^{30}$ demonstrated that STAT6 mediates the induction of CB1 gene by IL-4 in T lymphocytes. However, it has not been previously described that GEM treatment can activate STAT6, strongly suggesting that $C B 1$ and $C B 2$ gene induction by GEM occurs by a different mechanism. AS NF- $\kappa \mathrm{B}$ is one of the most important transcription factors induced by $G E M,{ }^{31}$ we analyzed the activation of $C B$ gene by GEM in the presence of the NF- $\kappa$ B inhibitors MG132, BAY, and PDTC. Both CB1 and $C B 2$ gene induction by GEM was totally prevented by these inhibitors, and IL-1, a known inducer of NF- $\kappa \mathrm{B}$, was able to activate $C B$ genes. Similar results were also obtained using $\mathrm{TNF}-\alpha$ (data not shown). As NF- $\kappa \mathrm{B}$ induction is described to be mediated by oxidative stress, we analyzed $C B$ gene induction by GEM in the presence of NAC. Our data show that NAC failed to prevent CB induction by GEM, indicating that GEM induces $C B$ gene expression by a ROS-independent mechanism. The molecular mechanism that is the basis of $\mathrm{NF}-\kappa \mathrm{B}$ induction by GEM is still unknown and its clarification needs additional investigations. 
a

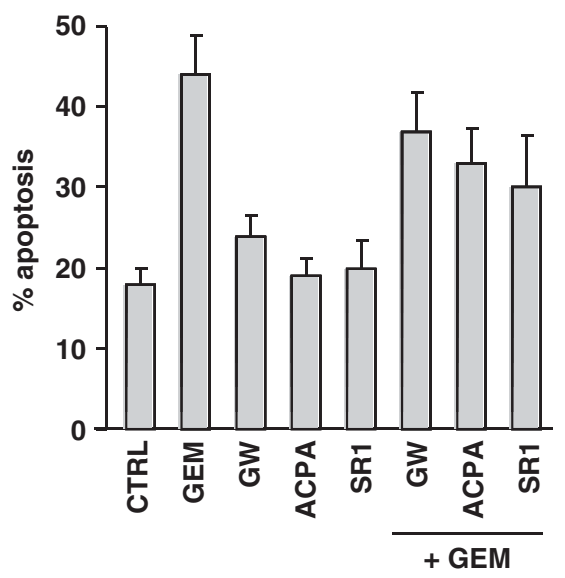

C

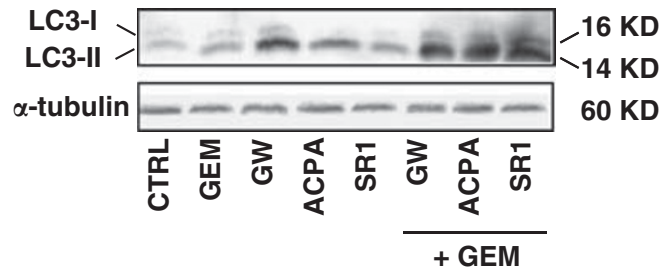

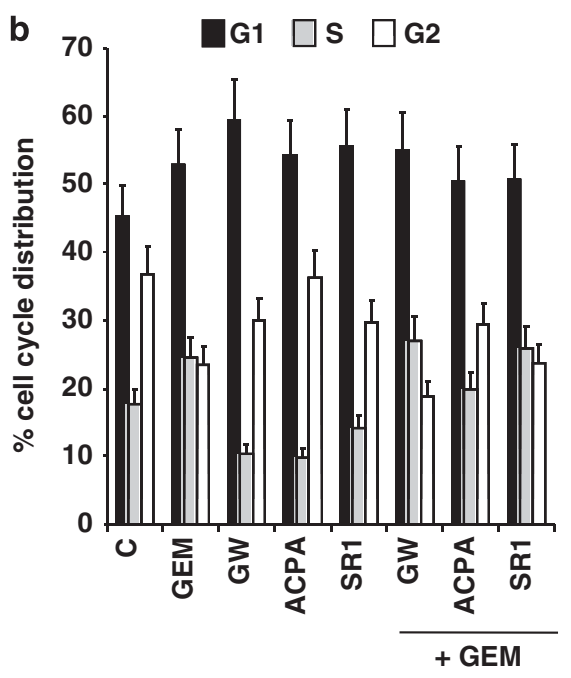

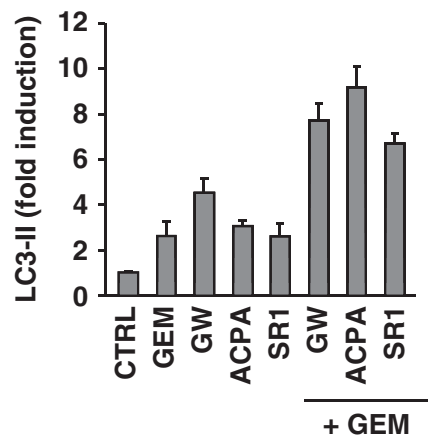

Figure 5 Analysis of apoptosis, cell cycle, and autophagy by GEM and/or cannabinoids. (a) Panc1 cells were treated with $200 \mathrm{nM} \mathrm{GEM} \mathrm{and/or} 16 \mu \mathrm{M}$ GW, $90 \mu \mathrm{M} \mathrm{ACPA}$, or $16 \mu \mathrm{M} \mathrm{SR} 1$ for $48 \mathrm{~h}$ and analyzed by flow cytometry to determine the percentages of apoptotic cells. Values are the means of three independent experiments ( \pm S.D.). Statistical analysis: $P<0.001$, control versus GEM; $P<0.05$, control versus each combination; $P<0.01$, GEM versus each combination, no significance between control and each cannabinoid. (b) Cells were treated with $200 \mathrm{nM}$ GEM and/or $16 \mu \mathrm{M} \mathrm{GW}, 90 \mu \mathrm{M}$ ACPA, or $16 \mu \mathrm{M}$ SR1 for $48 \mathrm{~h}$. Cell cycle distribution was analyzed by a flow cytometer after DNA staining with PI. Values are the means of three independent experiments ( \pm S.D.). Statistical analysis: no significance of GEM versus each combination. (c) Western blot analysis of LC3 was performed using total protein extracts from Panc1 cells treated with 500nM GEM and/or $40 \mu \mathrm{M} \mathrm{GW}, 225 \mu \mathrm{M} \mathrm{ACPA}$, or $40 \mu \mathrm{M}$ SR1 for $24 \mathrm{~h}$ in the presence of acid lysosomal protease inhibitors E64d $(10 \mu \mathrm{M})$ and pepstatin $\mathrm{A}(10 \mu \mathrm{g} / \mathrm{ml})$. Densitometric quantification of $\mathrm{LC} 3-\mathrm{Il}$ bands was normalized to $\alpha$-tubulin and performed, as described in Materials and Methods. Values are the means of triplicate samples from three independent experiments $( \pm S$.D.). Statistical analysis: $P<0.01$, control versus GW or ACPA; $P<0.05$, control versus SR1; and $P<0.01$, each cannabinoid versus its combination

The involvement of ER stress induction in cannabinoid antiproliferative effect has been already described. ${ }^{10}$ Accordingly, we report that the cannabinoids ACPA, GW, and SR1 activated the splicing of XBP-1 and inducted both Grp78 and CHOP genes, which are the molecular switch inducing apoptotic or autophagic cell death signals. ${ }^{17,18}$ Interestingly, we show that all the three ER stress-related genes induced by cannabinoids, including $\mathrm{CHOP}$, are additionally enhanced by GEM, supporting their involvement in GEM/cannabinoidmediated antiproliferative synergism.

It has been reported that $\mathrm{THC}$ induces caspase activation in pancreatic tumor cells. ${ }^{10}$ On the other hand, our data demonstrate that SR1, ACPA, or GW did not indeed induce apoptotic cell death, even if they induced cell cycle arrest at the G1 phase. The discrepancy between our results and those of Carracedo et al. ${ }^{10}$ may rely on the nature of $\mathrm{THC}$, which is a nonspecific cannabinoid receptor agonist, and requires additional investigations to be explained. Moreover, our results demonstrate that GEM-induced apoptosis was partially, but significantly, prevented by cannabinoids. As it has been reported that autophagy generally precedes apoptosis, ${ }^{32}$ one possible explanation may be that the stimulation of autophagy by SR1, ACPA, or GW or by their combinations with GEM is so elevated to inhibit the development of the apoptotic cell death program. In agreement with this hypothesis, the inhibition of autophagosome degradation by $C Q$ is reported to promote apoptosis in cancer cells. ${ }^{33}$ On the other hand, in line with the recent discovery that THC action induces autophagy-mediated cell death in human glioma cells, ${ }^{13}$ we describe that cannabinoids, as well as GEM, were able to induce autophagy in pancreatic cancer cells and that their combination strongly potentiated this effect. Our data also demonstrate that CQ or 3-MA addition to GEM significantly reduces the antiproliferative effects of the latter, supporting the concept that autophagy has a role in cancer cell growth inhibition in the present experimental model. These findings are in agreement with a recent demonstration that GEM is able to induce autophagy and LC3-II upregulation in pancreatic cancer cell lines. ${ }^{34}$ Autophagy induction by GEM may rely on the ability of GEM to stimulate sphingomyelinase or inhibit 
neutral ceramidase, enhancing the intracellular level of ceramide, ${ }^{35}$ a known inducer of autophagosome formation. The regulation of ceramide metabolism by GEM, coupled with the observation that the cannabinoid transduction pathway involves ceramide production, ${ }^{36}$ which, in turn, is able to induce oxidative stress, ${ }^{37}$ may be at the basis of the a
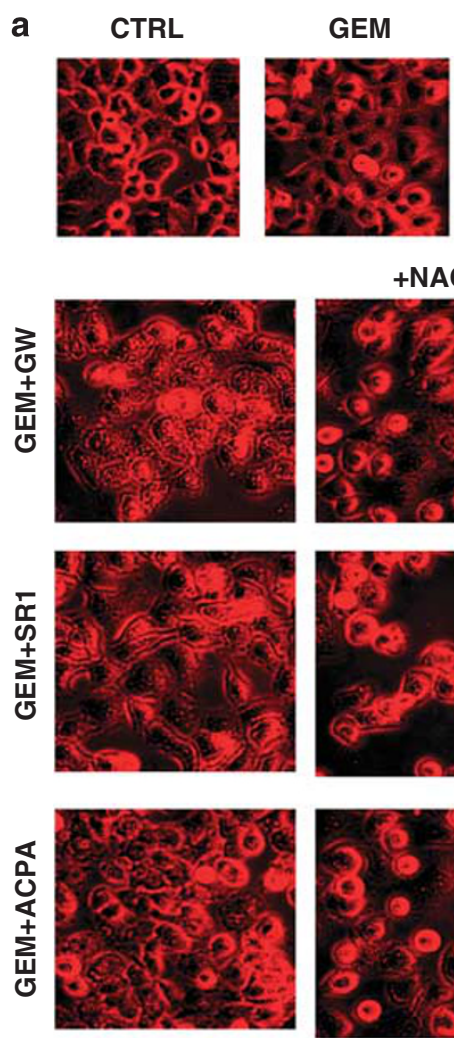

+NAC
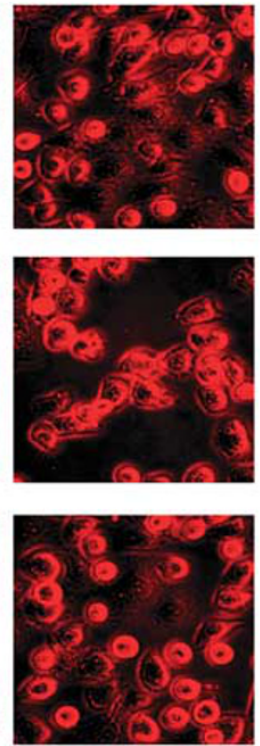

C

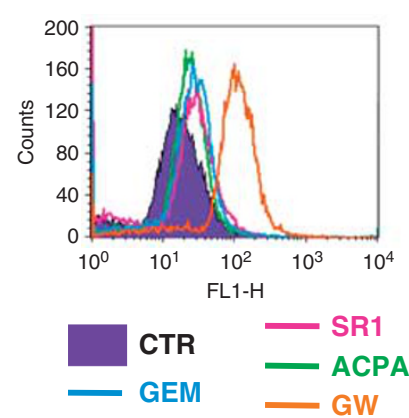

GW

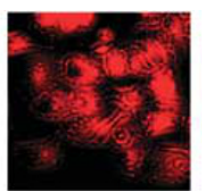

ACPA

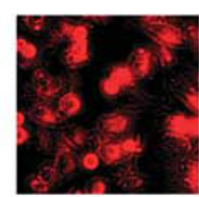

$+C Q$
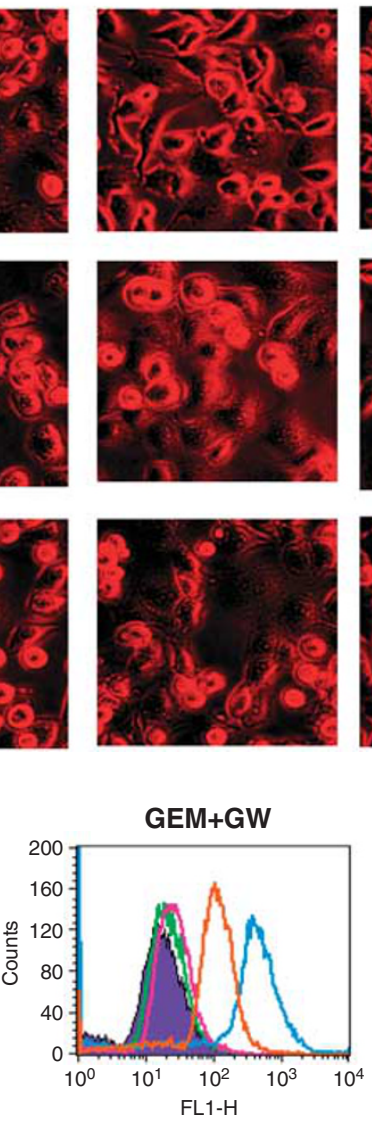

CTR

GEM + cannabinoids
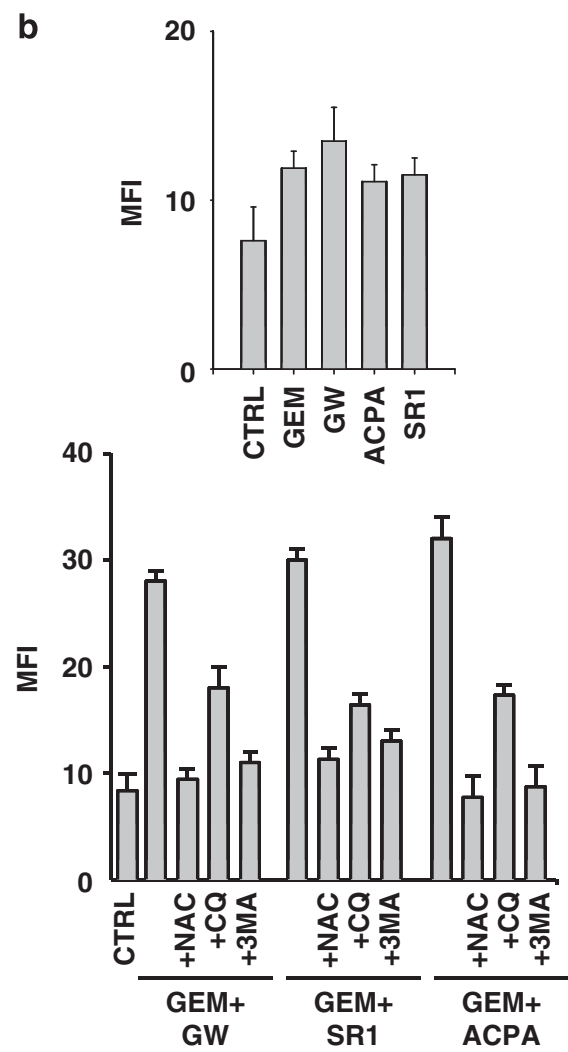
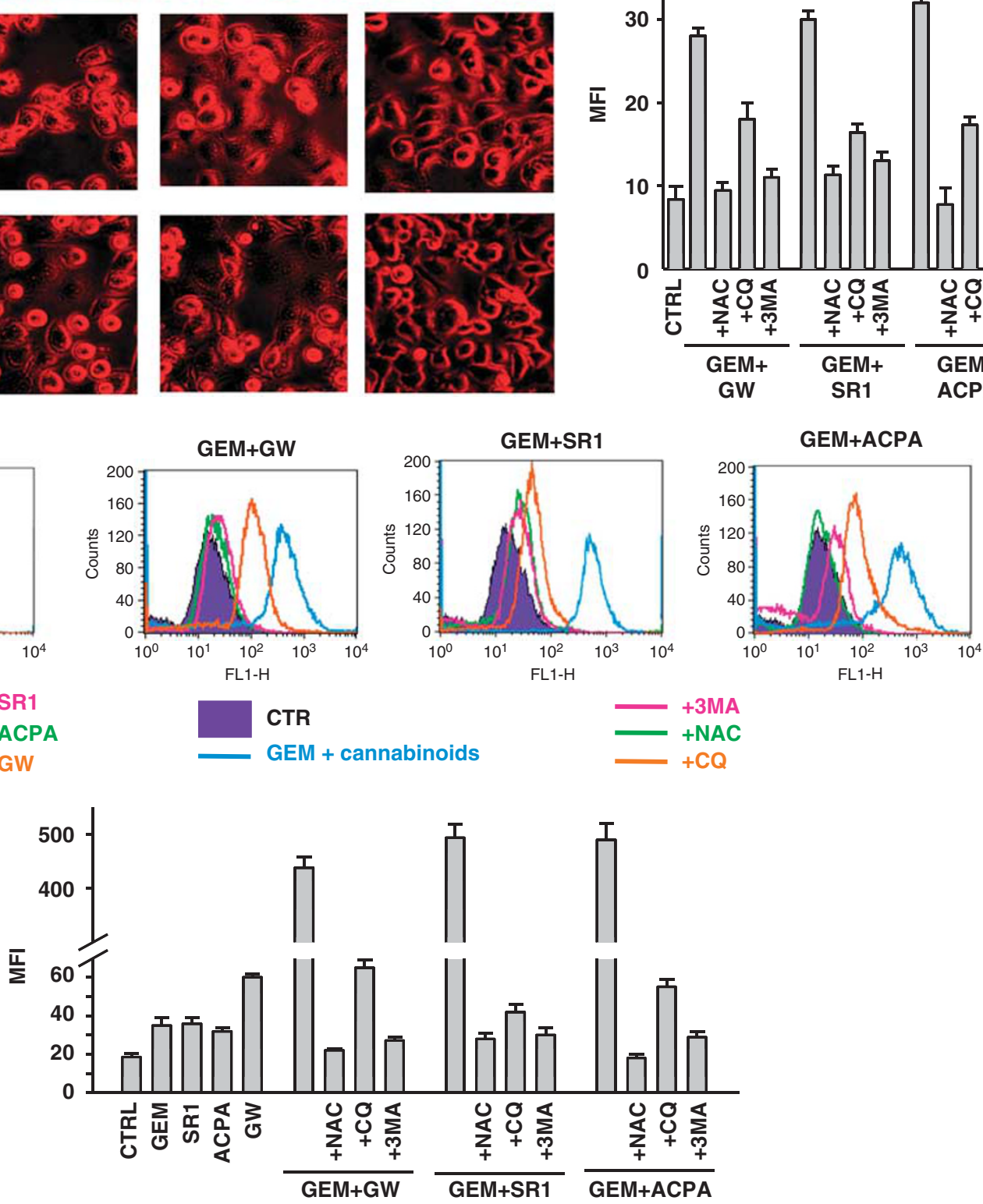
ROS-dependent synergistic autophagic cell death by GEM/ cannabinoid combinations.

Our kinetic studies revealed that ROS induction by drug combinations preceded the activation of the ER stress marker Grp78, which, in turn, preceded the autophagy marker LC3-II induction. The observation that LC3-II increase was prevented by NAC and that ROS could induce ER stress ${ }^{14}$ strongly supports the hypothesis that oxidative stress, ER stress, and autophagic cell death were sequential events in our experimental conditions.

For in vivo studies, we chose SR1, in addition to GEM, on the basis of its clinical relevance. ${ }^{25}$ Our in vivo experiments show that intraperitoneal injections of GEM + SR1 into nude mice bearing a subcutaneous mass of human pancreatic

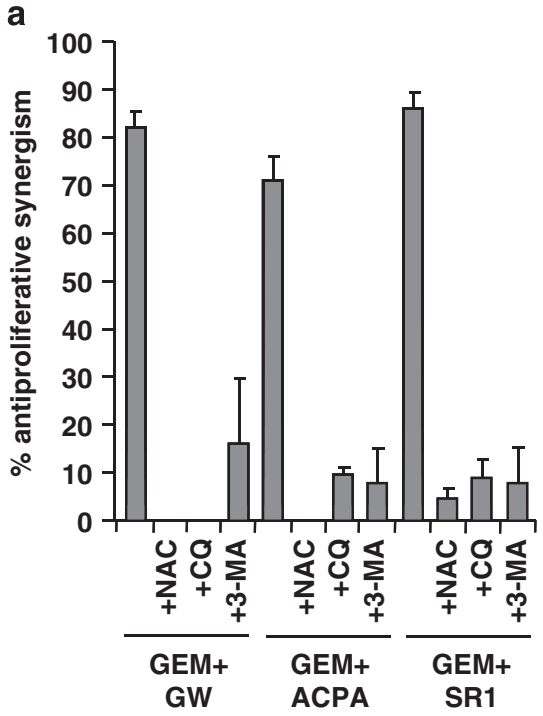

b

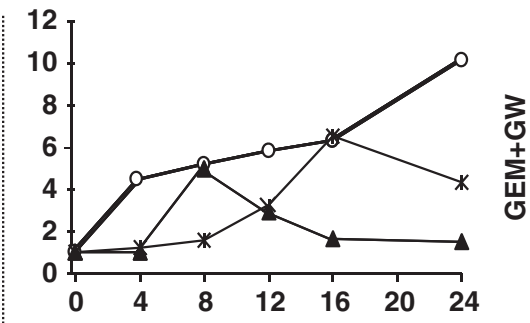

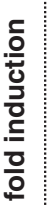
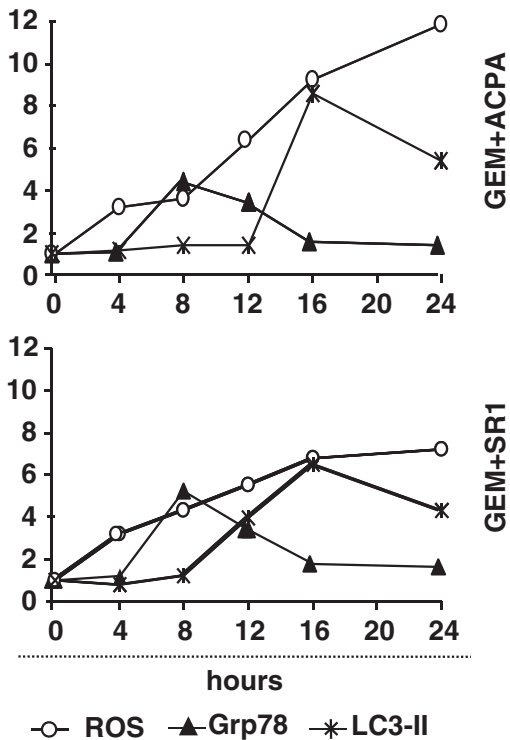

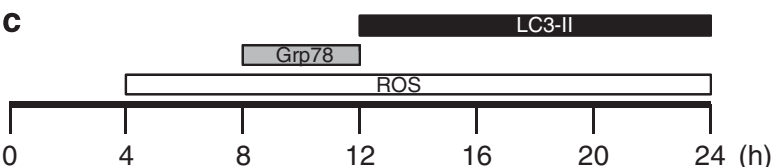

Figure 7 Involvement of ROS and autophagy in the antiproliferative synergism by GEM/cannabinoids and kinetic analysis of ROS, Grp78, and LC3-II induction by GEM/ cannabinoids. (a) Analysis of the antiproliferative synergism by $500 \mathrm{nM}$ GEM and $40 \mu \mathrm{M} \mathrm{GW}, 225 \mu \mathrm{M} \mathrm{ACPA}$, or $40 \mu \mathrm{M} \mathrm{SR} 1$ in the absence or presence of $20 \mathrm{mM}$ NAC or $10 \mu \mathrm{M} \mathrm{CQ}$ or $2.5 \mathrm{mM}$ 3-MA. Values are the means of three independent experiments ( \pm S.D.). Statistical analysis: $P<0.001$, GEM/cannabinoids versus GEM/ cannabinoids + NAC, GEM/cannabinoids + CQ, or GEM/cannabinoid + 3-MA. (b) Panc1 cells were treated with $500 \mathrm{nM}$ GEM and $40 \mu \mathrm{M}$ GW, $225 \mu \mathrm{M}$ ACPA, or $40 \mu \mathrm{M}$ SR1 for the indicated time points. ROS, Grp78, and LC3-II were analyzed, as described in Materials and Methods. Values are the means of three independent experiments. (c) Schematic representation of the kinetic analysis of oxidative stress (ROS), ER stress (Grp78), and autophagy (LC3-II) marker induction by GEM/cannabinoids

Figure 6 Involvement of ROS in GEM/cannabinoid-induced autophagy. (a) Fluorescence microscopy analysis of autophagosome formation in Panc1 cells after acridine orange staining treated with $500 \mathrm{nM}$ GEM and/or $40 \mu \mathrm{M} \mathrm{GW}, 225 \mu \mathrm{M} \mathrm{ACPA}$, or $40 \mu \mathrm{M}$ SR1 in the absence or presence of $20 \mathrm{mM}$ NAC or $10 \mu \mathrm{M}$ CQ or $1 \mathrm{mM} 3-\mathrm{MA}$ for $24 \mathrm{~h}$. (b) The MFIs were calculated, as described in 'Materials and Methods', at FACS after trypsinization of the acridine orange-labeled cells. Values are the means of triplicate samples from three independent experiments ( \pm S.D.). Statistical analysis: $P<0.05$, control versus GEM, GW, ACPA, or SR1; $P<0.001$, each cannabinoid or GEM versus their combination; and $P<0.001$, GEM/cannabinoids versus GEM/cannabinoids + NAC, GEM/cannabinoids $+\mathrm{CQ}$, or GEM/cannabinoid + 3-MA. (c) Flow cytometric analyses of autophagosomes formation (MDC incorporation) in Panc1 cells treated with $500 \mathrm{nM}$ GEM and/or $40 \mu \mathrm{M} \mathrm{GW}, 225 \mu \mathrm{M} \mathrm{ACPA}$, or $40 \mu \mathrm{M}$ SR1 in the absence or presence of $20 \mathrm{mM} \mathrm{NAC}$ or $10 \mu \mathrm{M} \mathrm{CQ}$ or $1 \mathrm{mM}$ 3-MA for $24 \mathrm{~h}$. The MFIs were calculated, as described in 'Materials and Methods'. Values are the means of three independent experiments ( \pm S.D.). Statistical analysis: $P<0.01$, control versus GEM, SR1, or ACPA; $P<0.001$, control versus GW; $P<0.001$, each cannabinoid or GEM versus their combination; and $P<0.001$, GEM/cannabinoids versus GEM/cannabinoids + NAC, GEM/cannabinoids + $\mathrm{CQ}$, or GEM/cannabinoid + 3-MA 

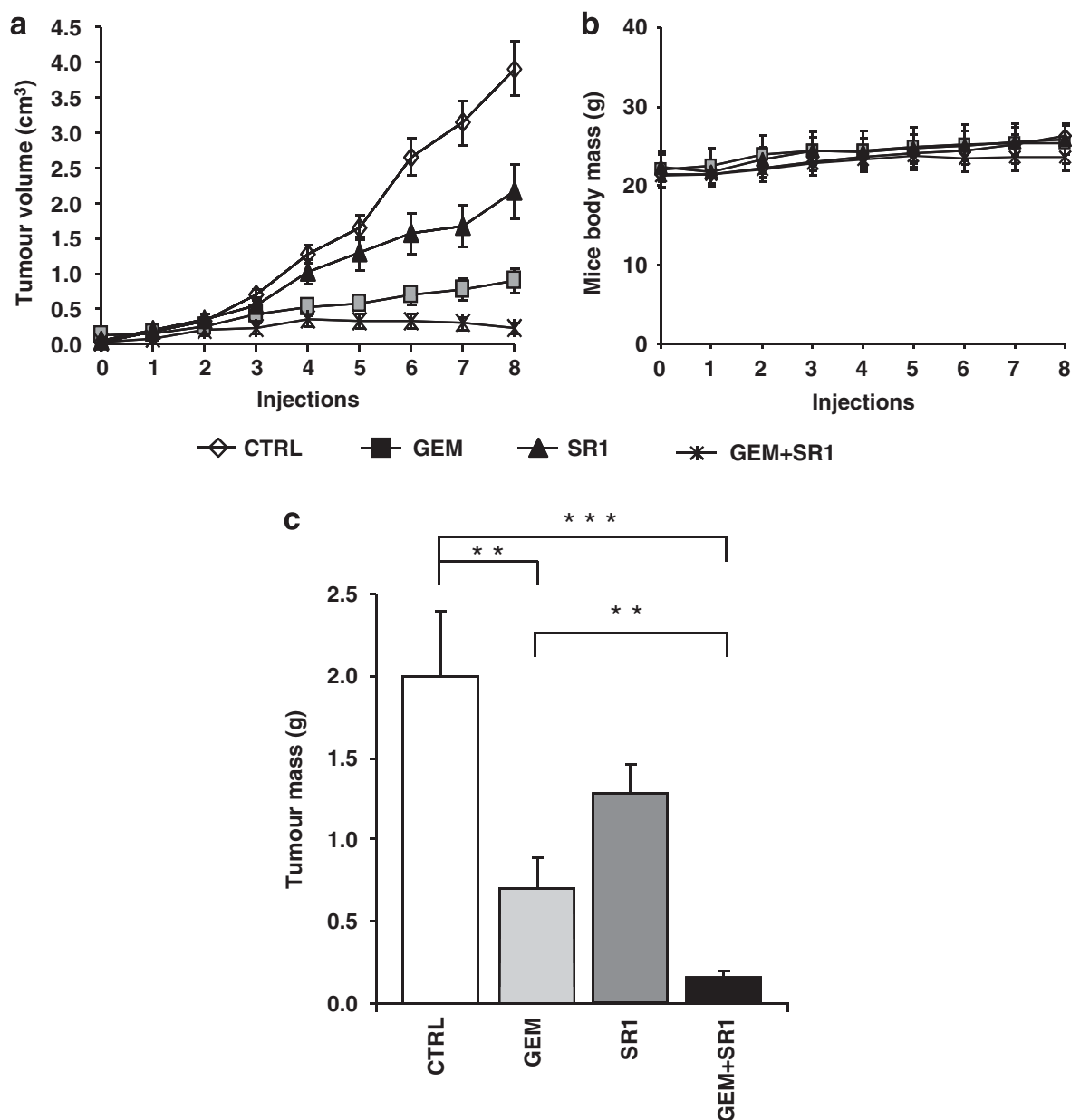

Figure 8 Effect of GEM + SR1 treatment on xenografts of PaCa44 cells in nude mice. Cells were subcutaneously injected into female nude mice. After 1 week, i.p. injections with PBS (solution vehicle), GEM, or/and SR1 were administered twice a week for 4 weeks, as described in Materials and Methods. (a) Values are the means of mice tumor volume measured at 3 days after each injection. (b) Values are the means of mice body mass measured at 3 days after each injection. (c) Values are the means of mice tumor mass ( \pm S.D.) measured after 8 injections

adenocarcinoma cells quite completely inhibited tumor growth. No apparent form of toxicity in vivo, such as mice death, body mass changes, or other apparent toxicity-related features, was observed in mice treated with GEM + SR1.

In conclusion, the results presented here provide the first evidence that the GEM/cannabinoid combinations exerted a strong synergistic antiproliferative effect on pancreatic adenocarcinoma GEM-resistant cell lines by ROS-dependent mechanisms, whereas it is scarcely toxic toward normal cells. Moreover, in vivo studies strongly boost the addition of cannabinoids to GEM in designing new therapeutic strategies for pancreatic cancer treatment.

\section{Materials and Methods}

Chemicals. GEM (Gemzar) was provided by Eli Lilly (Florence, Italy). SR141716 ( $\mathrm{N}$ (piperidino-1-yl)-5-(4-chlorophenyl)-1-(2,4dichlorophenyl)-4-methyl-pyrazole-3-carboxamide); SR1 (rimonabant; Acomplia, Sanofi-Aventis, Milan, Italy) was kindly provided by Dr. Maurizio Bifulco (University of Salemo, Italy); ACPA was obtained from Cayman Chemicals (Inalco, Milan, Italy); and GW405833 hydrochloride (1-(2,3-dichlorobenzoy)-2-methyl-3-(2(1-morpholine)ethyl)-5-methoxyindole; GW) from Sigma (Milan, Italy). ActD, PDTC, NAC, E64d, chloroquine diphosphate (CQ; $N^{4}$-(7-chloro-4-quinolinyl)- $N^{1}, N^{1}$-dimethyl-1,4pentanediamine), and 3-MA were obtained from Sigma. MG132 and BAY 11-7085 (2E)- 3-94-(1,1-dimethylethyl)-phenyl-sulfonyl-2-propenenitrile) (BAY) were obtained from Enzo Life Sciences (VinciBiochem, Florence, Italy), pepstatin A from AppliChem (Darmstadt, Germany), and the recombinant human IL-I from PeproTech (Inalco, Milan, Italy).

Cell culture. PaCa44, PaCa3, Panc1, CFPAC1, T3M4, and MiaPaCa2 cell lines ${ }^{38}$ were grown in RPMl 1640 supplemented with $2 \mathrm{mM}$ glutamine, $10 \%$ FBS, and $50 \mu \mathrm{g} / \mathrm{ml}$ gentamicin sulfate (BioWhittaker, Lonza, Bergamo, Italy), and incubated at $37^{\circ} \mathrm{C}$ with $5 \% \mathrm{CO}_{2}$. Normal primary fibroblasts (PromoCell, PBI, Milan, Italy) were grown in DMEM supplemented with $2 \mathrm{mM}$ glutamine, $10 \% \mathrm{FBS}$, and $50 \mu \mathrm{g} / \mathrm{ml}$ gentamicin sulfate, and were incubated at $37^{\circ} \mathrm{C}$ with $5 \% \mathrm{CO}_{2}$.

Cell proliferation assay. Cells were plated in 96-well cell culture plates $\left(5 \times 10^{3}\right.$ cells per well) and treated with various compounds, as indicated in the legends to figures. At the end of the treatments, cell proliferation was evaluated by Crystal Violet (Sigma) staining. The dye was solubilized in 1\% SDS in PBS and measured photometrically $\left(A_{595 \mathrm{~nm}}\right)$ to determine cell viability. Three or four independent experiments were performed for each assay condition.

Drug combination studies. The compounds were added for $48 \mathrm{~h}$ at the following concentration ranges: $1 \mathrm{nM}-1 \mu \mathrm{M}$ for GEM, $80 \mathrm{nM}-80 \mu \mathrm{M}$ for SR1 and GW, and $450 \mathrm{nM}-450 \mu \mathrm{M}$ for ACPA in GEM-resistant cell lines; $0.2 \mathrm{nM}-200 \mathrm{nM}$ for GEM, $100 \mathrm{nM}-100 \mu \mathrm{M}$ for SR1 and GW, and $560 \mathrm{nM}-560 \mu \mathrm{M}$ for ACPA in GEM-sensitive cell lines. The $\mathrm{Cl}$ was calculated by the Chou-Talalay equation, which takes into account both the potency $\left(\mathrm{IC}_{50}\right)$ and the shape of the dose-effect 
curve ${ }^{39}$ by using the CalcuSyn software. The general equation for the classic isobologram is given by $\mathrm{Cl}=(\mathrm{D}) 1 /(\mathrm{Dx}) 1+(\mathrm{D}) 2 /(\mathrm{Dx}) 2+((\mathrm{D}) 1(\mathrm{D}) 2) /((\mathrm{Dx}) 1 \cdot(\mathrm{Dx}) 2)$, where (Dx) 1 and (Dx)2 in the denominators are the doses (or concentrations) for D1 (drug 1) and D2 (drug 2) alone that give $\mathrm{x} \%$ growth inhibition, whereas (D)1 and (D)2 in the numerators are the doses of drug 1 and drug 2 in combination that also inhibited $\mathrm{x} \%$ cell viability (i.e., isoeffective). $\mathrm{Cl}<1$ and $\mathrm{Cl}<0.3$ indicated synergism and strong synergism, whereas $\mathrm{Cl}=1$ and $\mathrm{Cl}>1$ indicated additive effect and antagonism, respectively. Cl/effect curves represent the $\mathrm{Cl}$ versus the fraction (0-1) of cells killed by drug combination. The synergism percentage was obtained analyzing $\mathrm{Cl} /$ effect curve and measuring the $\mathrm{Cl}$ values at each 0.05 fraction, that is, $5 \%$ growth inhibition, of the antiproliferative effect. Throughout all the experiments, we obtained a linear correlation coefficient $(r)>0.90$. Drug combination studies were performed using the following concentration ratios: [GEM]:[SR1] and [GEM]:[GW] $=1: 500$ and [GEM]:[ACPA] $=1: 2800$ in GEM-sensitive cell lines, whereas [GEM]:[SR1] and [GEM]:[GW] $=1: 80$ and [GEM]:[ACPA] $=1: 450$ in GEM-resistant cell lines. These molar ratios were calculated on the basis of GEM and cannabinoid $\mathrm{IC}_{50}$ mean values at $48 \mathrm{~h}$. For GEM, they correspond to $36 \mathrm{nM}$ for the GEM-sensitive cell lines and $220 \mathrm{nM}$ for the GEM-resistant cell lines, as reported in our previous works. ${ }^{5}$ The three cannabinoids were all effective in the six cell lines, with $\mathrm{IC}_{50}$ mean values corresponding to $18 \mu \mathrm{M}$ for SR1 and GW and $100 \mu \mathrm{M}$ for ACPA. By inverting the molar ratios of the compounds between the two groups of cell lines, no significant alteration of the results was observed (data not shown), indicating that the data obtained were not influenced by the specific experimental condition tested.

Analysis of ROS. The non-fluorescent diacetylated $2^{\prime}, 7^{\prime}$-dichlorofluorescein (DCF-DA) probe (Sigma), which becomes highly fluorescent upon oxidation, was used to evaluate intracellular ROS production. Briefly, cells were plated in 96-well plates $\left(5 \times 10^{3}\right.$ cells per well) and, $24 \mathrm{~h}$ later, treated with various compounds, as indicated in the legends to figures. Then, cells were incubated with $10 \mu \mathrm{M}$ DCF-DA for $15 \mathrm{~min}$ at $37^{\circ} \mathrm{C}$, and the DCF fluorescence was measured by using a multimode plate reader (Ex $485 \mathrm{~nm}$ and $E m 535 \mathrm{~nm}$ ). Three independent experiments were performed for each assay condition.

RNA extraction qPCR, RT-PCR, and image analysis. Total RNA was extracted from $9 \times 10^{5}$ cells using TRIzol Reagent (Invitrogen, Milan, Italy), and $1 \mu \mathrm{g}$ of RNA was reverse transcribed using first-strand cDNA synthesis. Real-time quantification was performed in triplicate samples by SYBR Green detection chemistry with SYBR Green PCR Master Mix (Applied Biosystems, Invitrogen) on a 7000 Sequence Detection System. The primers used were: CB1For $5^{\prime}$-GAGAGGT GCCAAGGGAGCTT-3' and CB1Rev 5'-GGTGCGGAAGGTGGTATCTG-3'; CB2For $5^{\prime}$-CACAGCCTCTGTGGGTAGCC-3' and CB2Rev 5' ${ }^{\prime}$-ACGGGTGAGCA GAGCTTTGT-3'; Grp78For 5'-GACGGGCAAAGATGTCAGGAA-3' and Grp78Rev 5'-TCATAGTAGACCGGAACAGATCCA-3'; CHOPFor 5'-GCAGCCCATGAAGGA GAAAG-3' and CHOPRev $5^{\prime}$-CGGTCGATTTCCTGCTTGAG-3'; and GAPDHFor $5^{\prime}$-TGTGTCCGTCGTGGATCTGA-3' and GAPDHRev $5^{\prime}$-R-GATGCCTGCTTCAC CACCTT- $3^{\prime}$. The following cycling conditions were used: $95^{\circ} \mathrm{C}$ for $10 \mathrm{~min}, 40$ cycles at $95^{\circ} \mathrm{C}$ for $15 \mathrm{~s}, 60^{\circ} \mathrm{C}$ for $1 \mathrm{~min}$, and $72^{\circ} \mathrm{C}$ for $30 \mathrm{~s}$. The average of cycle threshold of each triplicate was analyzed according to the $2^{(-\Delta \Delta \mathrm{Ct})}$ method. For RT-PCR one-tenth of the CDNA was used as a template for PCR amplification using the following primers and cycling conditions: $\beta$-actinFor $5^{\prime}$-ACCAACTGGGACGACATGGAGAA-3 and $\beta$-actinRev $5^{\prime}$-GTGGTGGTGAAGCTGTAGCC- $3^{\prime}, 25$ cycles of $94^{\circ} \mathrm{C}$ for $60 \mathrm{~s}, 55^{\circ} \mathrm{C}$ for $60 \mathrm{~s}$, and $72^{\circ} \mathrm{C}$ for $60 \mathrm{~s}$; XBP-1For $5^{\prime}$-CCTTGTAGTTGAGAACCAGG-3' and XBP1Rev $5^{\prime}$-GGGGCTTGGTATATATGTGG- $3^{\prime}, 40$ cycles of $93^{\circ} \mathrm{C}$ for $60 \mathrm{~s}, 55^{\circ} \mathrm{C}$ for $60 \mathrm{~s}$, and $72^{\circ} \mathrm{C}$ for $60 \mathrm{~s}$. PCR products were separated by electrophoresis through ethidium bromide-stained $3.5 \%$ agarose gel and visualized by ultraviolet light. To quantify XBP-1 splicing, XBP-1(S) bands were scanned as digital peaks and the areas of the peaks were calculated using the public domain NIH Image software (http://imagej.nih.gov), normalized with $\beta$-actin mRNA expression, and reported as fold induction relative to controls.

For ActD experiments, $2.5 \times 10^{5}$ Panc1 cells were seeded in $60-\mathrm{mm}$ plates and incubated overnight. Cells were pretreated with $5 \mu \mathrm{g} / \mathrm{ml} \mathrm{ActD}$ for $1 \mathrm{~h}$, then $2 \mu \mathrm{M}$ GEM was added, and the treatments prolonged up to $16 \mathrm{~h}$. Total RNA extraction and real-time PCR were performed, as above described.

Apoptosis. The percentage of apoptotic cells was evaluated by staining $3 \times 10^{5}$ cells with annexin V-FITC (Bender Med System, Prodotti Gianni, Milan, Italy) and $5 \mu \mathrm{g} / \mathrm{ml} \mathrm{PI}$ in binding buffer (10 mM HEPES/NaOH $(\mathrm{pH} 7.4), 140 \mathrm{mM} \mathrm{NaOH}$, and $2.5 \mathrm{mM} \mathrm{CaCl}_{2}$ ) for $10 \mathrm{~min}$ at room temperature in the dark. The samples were analyzed by flow cytometry (FACScalibur, Becton Dickinson, San Jose, CA, USA) to determine the percentage of cells displaying annexin $\mathrm{V}+/ \mathrm{PI}-$ (early apoptosis) or annexin $\mathrm{V}+/ \mathrm{PI}+$ staining (late apoptosis). For each sample, we report the percentage values corresponding to the addition of early and late apoptosis. Three independent experiments were performed for each assay condition.

Cell cycle analysis. Cell cycle distribution was analyzed by staining $3 \times 10^{5}$ cells with PI. After the indicated treatments, cells were washed with PBS, incubated with $0.1 \%$ sodium citrate dihydrate, $0.1 \%$ Triton X-100, $200 \mu \mathrm{g} / \mathrm{ml}$ RNase A, $50 \mu \mathrm{g} / \mathrm{ml} \mathrm{PI}$ (Roche Diagnostics, Milan, Italy), and analyzed using a flow cytometer (FACScalibur, Becton Dickinson). The percentage of cells in the various stages of the cell cycle was determined using the ModFitLT software (Verity Software House, Topsham, ME, USA). Three independent experiments were performed for each assay condition.

Immunoblot analysis. In all, $1.2 \times 10^{6}$ cells were treated with the various compounds, as indicated in the legends to figures, collected, washed in PBS, and resuspended in RIPA buffer, pH 8 (150 mM NaCl, pH 8; 50 mM Tris-HCl; 1\% NP-40; $0.5 \% \mathrm{Na}-\mathrm{Doc}$; and $0.1 \% \mathrm{SDS}$ ), $1 \mathrm{mM} \mathrm{PMSF}, 1 \mathrm{mM} \mathrm{Na}_{3} \mathrm{VO}_{4}, 1 \mathrm{mM} \mathrm{NaF}, 2.5 \mathrm{mM}$ EDTA, and $1 \times$ protease inhibitor cocktail (Roche Diagnostics) for 30 min on ice. The lysate was centrifuged at $14000 \times g$ for $10 \mathrm{~min}$ at $4^{\circ} \mathrm{C}$, and the supernatant was used for western blot. Protein concentration was measured with the Bradford protein assay reagent (Pierce, Celbio, Milan, Italy) using bovine serum albumin as standard. Fifty (for LC3-II) or thirty (for Grp78) micrograms of protein extracts were electrophoresed through a $15 \%$ SDS-polyacrylamide gel and electroblotted onto PVDF membranes (Millipore, Milan, Italy). Membranes were then incubated for $2 \mathrm{~h}$ at room temperature with blocking solution ( $5 \%$ low-fat milk in TBST (100 mM Tris, $\mathrm{pH} 7.5,0.9 \% \mathrm{NaCl}$, and $0.1 \%$ Tween 20$)$ ) and probed overnight at $4{ }^{\circ} \mathrm{C}$ with the appropriate primary antibody (1:1000 in blocking solution of LC3B (Cell Signaling, Milan, Italy), Grp78 (Santa Cruz Biotechnology, DBA, Milan, Italy), or $\alpha$-tubulin (oncogene) antibodies). Horseradish peroxidase-conjugated IgG (1:2000 in blocking solution, Upstate Biotechnology, Milan, Italy) was used to detect specific proteins. Immunodetection was carried out using chemiluminescent substrates (Amersham Pharmacia Biotech, Milan, Italy) and recorded using a Hyperfilm ECL (Amersham Pharmacia Biotech). To quantify LC3-II and Grp78 expression, bands were scanned as digital peaks and the areas of the peaks were calculated in arbitrary units using the public domain NIH Image software (http://rsb.info.nih.gov/ nihimage/), normalized with $\alpha$-tubulin expression, and reported as fold induction relative to controls.

Labeling of autophagic vacuoles with MDC. To quantify the induction of the autophagic process in Panc-1 cells treated with the various compounds as indicated in the legend, MDC staining was performed, as previously described. ${ }^{40}$ Following the treatments, cells were incubated with $50 \mu \mathrm{M} \mathrm{MDC}$ in PBS at $37^{\circ} \mathrm{C}$ for 15 min. After incubation, cells were washed with PBS, trypsinized, and immediately analyzed by flow cytometry. All fluorescences were analyzed with a FACScalibur flow cytometer (Becton Dickinson). The fluorescent emissions were collected through a $530 \mathrm{~nm}$ band pass filter (FL1 channel). At least 10000 events were acquired in log mode. For the quantitative evaluation of MDC, CellQuest software (Becton Dickinson) was used to calculate mean fluorescence intensities (MFIs). The MFIs were calculated by the formula (MFItreated/MFIcontrol), where MFItreated is the fluorescence intensity of cells treated with the various compounds and MFIcontrol is the fluorescence intensity of untreated and unstained cells. Values reported in the figures are the means \pm S.D.s from three independent experiments.

Quantification of AVOs with acridine orange. In acridine orangestained cells, the cytoplasm and nucleus are bright green and dim red, whereas acidic compartments are bright red. The intensity of the red fluorescence is proportional to the degree of acidity. Following the treatments, as specified in the legend, cells were incubated with acridine orange solution $(1 \mu \mathrm{g} / \mathrm{ml})$ at $37^{\circ} \mathrm{C}$; after $15 \mathrm{~min}$ in drug-free medium at $37^{\circ} \mathrm{C}$, they were washed with PBS, immediately stained with $1 \mu \mathrm{g} / \mathrm{ml}$ of acridine orange for $15 \mathrm{~min}$, and observed with a Nikon Eclipse TE300 Inverted microscope (Nikon Instruments, Inc., Melville, NY, USA). Then, cells were trypsinized and analyzed by flow cytometry using FACScan cytometer and CellQuest software, as previously described. Statistical analyses were performed, as described above.

In vivo studies. On the basis of our previous experience, we could not make use of Panc1 cells for in vivo studies because of their low growth rate in nude mice. 
Thus, we chose PaCa44 cells because of their similar behavior to Panc1 cells in in vitro growth inhibition studies. PaCa44 cells $\left(2 \times 10^{6}\right.$ cells/mice $)$ were s.c. injected into female nude mice (4 weeks of age, Harlan laboratories, Udine, Italy). One week after cell inoculation, five randomized animals for each experimental group received solution vehicle (PBS), $25 \mathrm{mg} / \mathrm{kg}$ GEM, or $/$ and $0.28 \mathrm{mg} / \mathrm{kg}$ SR 1 by intraperitoneal injection biweekly for 4 weeks. Drug doses were chosen on the basis of their respective clinical use following US Food and Drug Administration directives. Tumor volume and body mass were biweekly recorded for each animal. Animals were killed at the end of the 4-week study period, and the tumors were resected and weighted. Animal studies were approved by the Verona University Review Board.

Statistical analysis. ANOVA (post hoc Bonferroni) analysis was performed by GraphPad Prism 5 (GraphPad Software, Inc., La Jolla, CA, USA). P-values $<0.05$, 0.01 , or 0.001 were indicated as ${ }^{*},{ }^{* \star}$, or ${ }^{* * *}$, respectively.

\section{Conflict of Interest}

The authors declare no conflict of interest.

Acknowledgements. This work was supported by Associazione Italiana Ricerca Cancro, Milan, Italy; Fondazione CariPaRo, Padova, Italy; Joint Project of University of Verona, Verona, Italy; and MIUR, PRIN 2008 (Alberto Abbruzzese). SR141716 (Rimonabant) was provided by Sanofi-Aventis (grant to M Bifulco, no. 051309). We thank Dr. Federica Cioffi (University of Verona) for FACS analysis support, and Dr. Giorgio Malpeli (University of Verona) for qPCR technical support.

1. Li J, Merl MY, Chabot J, Saif MW. Updates of adjuvant therapy in pancreatic cancer: where are we and where are we going? Highlights from the '2010 ASCO Annual Meeting'. Chicago, IL, USA. JOP 2010; 11: 310-312.

2. Neoptolemos JP, Cunningham D, Friess H, Bassi C, Stocken DD, Tait DM et al. Adjuvant therapy in pancreatic cancer: historical and current perspectives. Ann Oncol 2003; 14: 675-692.

3. Burris III HA, Moore MJ, Andersen J, Green MR, Rothenberg ML, Modiano MR et al. Improvements in survival and clinical benefit with gemcitabine as first-line therapy for patients with advanced pancreas cancer: a randomized trial. J Clin Oncol 1997; 15: 2403-2413.

4. Laurent A, Nicco C, Chereau C, Goulvestre C, Alexandre J, Alves A et al. Controlling tumor growth by modulating endogenous production of reactive oxygen species. Cancer Res 2005; 65: 948-956.

5. Donadelli M, Costanzo C, Beghelli S, Scupoli MT, Dandrea M, Bonora A et al. Synergistic inhibition of pancreatic adenocarcinoma cell growth by trichostatin $A$ and gemcitabine. Biochim Biophys Acta 2007; 1773: 1095-1106.

6. Casanova ML, Blazquez C, Martinez-Palacio J, Villanueva C, Fernandez-Acenero MJ, Huffman JW et al. Inhibition of skin tumor growth and angiogenesis in vivo by activation of cannabinoid receptors. J Clin Invest 2003; 111: 43-50.

7. De Petrocellis L, Melck D, Palmisano A, Bisogno T, Laezza C, Bifulco M et al. The endogenous cannabinoid anandamide inhibits human breast cancer cell proliferation. Proc Natl Acad Sci USA 1998; 95: 8375-8380.

8. Matsuda LA, Lolait SJ, Brownstein MJ, Young AC, Bonner TI. Structure of a cannabinoid receptor and functional expression of the cloned cDNA. Nature 1990; 346: 561-564.

9. Munro S, Thomas KL, Abu-Shaar M. Molecular characterization of a peripheral receptor for cannabinoids. Nature 1993; 365: 61-65.

10. Carracedo A, Gironella M, Lorente M, Garcia S, Guzman M, Velasco G et al. Cannabinoids induce apoptosis of pancreatic tumor cells via endoplasmic reticulum stress-related genes. Cancer Res 2006; 66: 6748-6755.

11. Sarker KP, Obara S, Nakata M, Kitajima I, Maruyama I. Anandamide induces apoptosis of PC-12 cells: involvement of superoxide and caspase-3. FEBS Lett 2000; 472: 39-44.

12. Costa $B$, Colleoni $M$. Changes in rat brain energetic metabolism after exposure to anandamide or Delta(9)-tetrahydrocannabinol. Eur J Pharmacol 2000; 395: 1-7.

13. Salazar M, Carracedo A, Salanueva IJ, Hernandez-Tiedra S, Lorente M, Egia A et al. Cannabinoid action induces autophagy-mediated cell death through stimulation of ER stress in human glioma cells. J Clin Invest 2009; 119: 1359-1372.

14. Yokouchi M, Hiramatsu N, Hayakawa K, Okamura M, Du S, Kasai A et al. Involvement of selective reactive oxygen species upstream of proapoptotic branches of unfolded protein response. J Biol Chem 2008; 283: 4252-4260.

15. Rutkowski DT, Kaufman RJ. That which does not kill me makes me stronger: adapting to chronic ER stress. Trends Biochem Sci 2007; 32: 469-476.

16. Kaufman RJ. Orchestrating the unfolded protein response in health and disease. J Clin Invest 2002; 110: 1389-1398.

17. Schonthal $\mathrm{AH}$. Endoplasmic reticulum stress and autophagy as targets for cancer therapy. Cancer Lett 2009; 275: 163-169.

18. Puthalakath H, O'Reilly LA, Gunn P, Lee L, Kelly PN, Huntington ND et al. ER stress triggers apoptosis by activating BH3-only protein Bim. Cell 2007; 129: 1337-1349.

19. Rouschop KM, van den Beucken T, Dubois L, Niessen H, Bussink J, Savelkouls K et al. The unfolded protein response protects human tumor cells during hypoxia through regulation of the autophagy genes MAP1LC3B and ATG5. J Clin Invest 2010; 120: $127-141$.

20. Kondo Y, Kondo S. Autophagy and cancer therapy. Autophagy 2006; 2: 85-90.

21. Massi P, Vaccani A, Bianchessi S, Costa B, Macchi P, Parolaro D. The non-psychoactive cannabidiol triggers caspase activation and oxidative stress in human glioma cells. Cell $\mathrm{Mol}$ Life Sci 2006; 63: 2057-2066.

22. Biederbick A, Kern HF, Elsasser HP. Monodansylcadaverine (MDC) is a specific in vivo marker for autophagic vacuoles. Eur J Cell Biol 1995; 66: 3-14.

23. Xie S, Furjanic MA, Ferrara JJ, McAndrew NR, Ardino EL, Ngondara A et al. The endocannabinoid system and rimonabant: a new drug with a novel mechanism of action involving cannabinoid CB1 receptor antagonism - or inverse agonism-as potential obesity treatment and other therapeutic use. J Clin Pharm Ther 2007; 32: 209-231.

24. Krylatov AV, Maslov LN, Lasukova OV, Pertwee RG. Cannabinoid receptor antagonists SR141716 and SR144528 exhibit properties of partial agonists in experiments on isolated perfused rat heart. Bull Exp Biol Med 2005; 139: 558-561.

25. Bifulco M, Grimaldi C, Gazzerro P, Pisanti S, Santoro A. Rimonabant: just an antiobesity drug? Current evidence on its pleiotropic effects. Mol Pharmacol 2007; 71: 1445-1456.

26. Bifulco M, Laezza C, Valenti M, Ligresti A, Portella G, V DIM. A new strategy to block tumor growth by inhibiting endocannabinoid inactivation. Faseb J 2004; 18: 1606-1608.

27. Donadelli M, Dalla Pozza E, Costanzo C, Scupoli MT, Piacentini P, Scarpa A et al. Increased stability of P21(WAF1/CIP1) mRNA is required for ROS/ERK-dependent pancreatic adenocarcinoma cell growth inhibition by pyrrolidine dithiocarbamate. Biochim Biophys Acta 2006; 1763: 917-926.

28. Donadelli M, Dalla Pozza E, Scupoli MT, Costanzo C, Scarpa A, Palmieri M. Intracellular zinc increase inhibits $\mathrm{p} 53(-/-)$ pancreatic adenocarcinoma cell growth by ROS/AIFmediated apoptosis. Biochim Biophys Acta 2009; 1793: 273-280.

29. Shi Y, Zou M, Baitei EY, Alzahrani AS, Parhar RS, Al-Makhalafi Z et al. Cannabinoid 2 receptor induction by $\mathrm{LL}-12$ and its potential as a therapeutic target for the treatment of anaplastic thyroid carcinoma. Cancer Gene Ther 2008; 15: 101-107.

30. Borner $\mathrm{C}$, Bedini A, Hollt V, Kraus $\mathrm{J}$. Analysis of promoter regions regulating basal and interleukin-4-inducible expression of the human CB1 receptor gene in T lymphocytes. $\mathrm{Mol}$ Pharmacol 2008; 73: 1013-1019.

31. Arlt A, Gehrz A, Muerkoster S, Vorndamm J, Kruse ML, Folsch UR et al. Role of NFkappaB and $A k t / P I 3 K$ in the resistance of pancreatic carcinoma cell lines against gemcitabine-induced cell death. Oncogene 2003; 22: 3243-3251.

32. Maiuri MC, Zalckvar E, Kimchi A, Kroemer G. Self-eating and self-killing: crosstalk between autophagy and apoptosis. Nat Rev Mol Cell Biol 2007; 8: 741-752.

33. Boya P, Gonzalez-Polo RA, Casares N, Perfettini JL, Dessen P, Larochette N et al. Inhibition of macroautophagy triggers apoptosis. Mol Cell Biol 2005; 25: 1025-1040.

34. Mukubou H, Tsujimura T, Sasaki R, Ku Y. The role of autophagy in the treatment of pancreatic cancer with gemcitabine and ionizing radiation. Int J Oncol 2010; 37: 821-828.

35. Wu BX, Zeidan YH, Hannun YA. Downregulation of neutral ceramidase by gemcitabine: implications for cell cycle regulation. Biochim Biophys Acta 2009; 1791: 730-739.

36. Galve-Roperh I, Sanchez C, Cortes ML, Gomez del Pulgar T, Izquierdo M, Guzman M. Anti-tumoral action of cannabinoids: involvement of sustained ceramide accumulation and extracellular signal-regulated kinase activation. Nat Med 2000; 6: 313-319.

37. Garcia-Ruiz C, Colell A, Mari M, Morales A, Fernandez-Checa JC. Direct effect of ceramide on the mitochondrial electron transport chain leads to generation of reactive oxygen species. Role of mitochondrial glutathione. J Biol Chem 1997; 272: 11369-11377.

38. Moore PS, Sipos B, Orlandini S, Sorio C, Real FX, Lemoine NR et al. Genetic profile of 22 pancreatic carcinoma cell lines. Analysis of K-ras, p53, p16 and DPC4/Smad4. Virchows Arch 2001; 439: 798-802.

39. Chou TC, Talalay P. Quantitative analysis of dose-effect relationships: the combined effects of multiple drugs or enzyme inhibitors. Adv Enzyme Regul 1984; 22: 27-55.

40. Meschini S, Condello M, Calcabrini A, Marra M, Formisano G, Lista $P$ et al. The plant alkaloid voacamine induces apoptosis-independent autophagic cell death on both sensitive and multidrug resistant human osteosarcoma cells. Autophagy 2008; 4: 1020-1033.

(c)

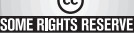

Cell Death and Disease is an open-access journal published by Nature Publishing Group. This work is licensed under the Creative Commons Attribution-Noncommercial-No Derivative Works 3.0 Unported License. To view a copy of this license, visit http://creativecommons.org/licenses/by-nc-nd/3.0/

\section{Supplementary Information accompanies the paper on Cell Death and Disease website (http://www.nature.com/cddis)}

